\title{
Study of damage distribution and intensity in regions of the facade
}

\author{
Jessica S. de Souza $^{1} \cdot$ Elton Bauer $^{1}\left(\right.$ ID $^{*}$ Matheus L. M. Nascimento $^{1} \cdot$ \\ Valdirene M. S. Capuzzo ${ }^{1} \cdot$ Vanda A. G. Zanoni ${ }^{2}$
}

Received: 22 June 2016/Accepted: 30 August 2016/Published online: 15 September 2016

(C) Springer International Publishing Switzerland 2016

\begin{abstract}
The ceramic coating systems applied to building facades have relevant aesthetic value and protection functions. The architectural and environmental conditions can greatly influence the degradation process of the facades, which may pose risks and compromise the durability and service life of the building and its components. The degradation process of facades changes according to the region where it takes place. To this end, the present study aims to determine damage intensity and distribution in the different regions of the facade. This study investigated the facades of three buildings that are part of the Materials Testing Laboratory (LEM) database of the Universidade de Brasilia. The degradation was quantified using a methodology proposed by Silva (2014) to generate a degradation index expressed in $\mathrm{m}^{2}$. After the quantification of damages, few indexes associated with the percentage of degraded area, applied to the facade regions, are presented. These weighted indexes allowed to standardize the values observed in each region. Obtaining these indices is fundamental to the study of degradation. The results show that for a comparative analysis between the regions, the observed values should be corrected for the proportionality of the area of each region in relation to the total area of the facade. It was also noted that the continuous walls are the
\end{abstract}

Elton Bauer

elbauerlem@gmail.com

1 Post-Graduate Program in Structures and Civil Construction, Civil and Environmental Engineering Department, University of Brasília, Campus Universitário Darcy Ribeiro, Asa Norte, 70910-900 Brasília, DF, Brazil

2 Faculty of Architecture and Urbanism, University of Brasília, Campus Universitário Darcy Ribeiro, Asa Norte, 70910-900 Brasília, DF, Brazil most affected regions, but they do not always present the highest damage intensity.

Keywords Pathology · Degradation · Facades ·

Degradation index $\cdot$ Damage distribution

\section{Introduction}

Buildings must be designed to meet all requirements demanded to achieve the lifetime for which they were designed. However, they begin to deteriorate from the time they start being used, showing a progressive loss of performance until they become ineffective $[1,2]$. Consequently, there is growing concern about the durability and service life of buildings, mainly for economic and environmental reasons.

The different situations of each building make degradation particular and unique to each building, or to each individual building facade, even for buildings constructed under the same conditions [3, 4]. This different degradation rate is justified by the existence of numerous conditions that influence the degradation process, such as design constraints, microclimate and whether the regions are sheltered or not. To study durability, it is necessary to use a simultaneous approach regarding the performance of elements and the interactions between the systems, such as the facade coating and other components, and elements [5].

Degradation is often heightened by errors that occur during the different stages of the construction process, such as planning, design, specification, materials, execution and use (operation and maintenance). For example, several problems may result and directly affect facade durability when joints are not properly placed and sized according to the acting forces, during the design phase [6]. It is 
emphasized that it is extremely difficult to consider all variables that affect durability, thus hindering the understanding of the degradation phenomenon. Therefore, the study of degradation becomes important and can be of great use to the construction science [7, 8].

The ISO 15686 standards (Building and construction assets-service life planning) identified and established principles for the provision of service life and systematize a building planning framework through the service life. It is, therefore, a fundamental reference for studying the service life of buildings [4, 9, 10]. The ISO 15686-2 [11] standard addresses systematically, service life prediction methodology of building components and procedures, based on the technical and functional performance, which facilitates predicting the service life of building components.

The Brazilian standard NBR 15575-1 [12] establishes durability as one of the performance requirements, qualitatively, and service life as one of the criteria of durability, quantitatively. Thus, the durability study is directly related to the expected service life.

Degradation studies and measurement methodologies are auxiliary tools to predict service life, and to determine maintenance requirements [13]. The degradation curves are one of the tools used to predict service life since they reflect the speed at which the systems start to fail and stop meeting the minimum requirements [14-16]. The main objective of the degradation curves is to monitor the performance over time. Usually, the behavior is graphically expressed by degradation rates over time, represented by the degradation curve. The degradation index is the combination of degradation action responses in buildings. Thus, this indicator should be able to measure the existing degradation level of the building systems or components [9, 17].

The degradation process can be accelerated or reduced depending on the exposure conditions, of the sensitivity to degradation of components, and maintenance interventions [18]. The envelope of the building is the first obstacle encountered by external degradation agents, resulting in greater loss of performance of external components than in other systems or components of the building [19, 20]. The major external agents of degradation are the climatic agents, such as the action of the environment and whose effects are dependent on the climate and microclimate around the building. The main climatic agents are driving rain, wind, radiation and temperature gradient [21, 22].

The degradation process of facades does not occur uniformly due to the different demands and different exposure of each facade region or component. It is noteworthy that degradation of the top regions is different from that of the balconies since the exposure conditions are different, thus becoming necessary specific studies in each area. It is important to note that the exposure conditions, location, and level of severity of the conditions influence the non-uniformity of the degradation process of the facades [23].

Several researchers have been studying the degradation phenomenon. Silva [4], Gaspar [9] and Galbusera [24] investigated which conditions influence the degradation process and degradation behavior over time. The studies of Silva [16], Antunes [25], and Souza [26] dealt with durability and degradation characteristics observed in buildings in different situations. Antunes [25] presented the most common pathologies in ceramic tiling facades and proved the relationship between certain anomalies and their location. Silva [16] associated the level of degradation to different exposures of each orientation. Souza [26] used degradation indicators and reported that some regions of the facades are more sensitive to degradation.

Even as the studies advance, understanding the evolution of buildings' degradation needs further scientific studies since unexpected behavior occurs, especially in different cities. Building inspections show anomalies and allow observing the degradation patterns and trends along the facades, thus helping to prevent and finding ways to repair it [27]. One of the great advantages of obtaining degradation data through the inspection of buildings is the direct correlation between the state of the components, the exposure environment and the use of the building [26].

The incidence of anomalies is different for the different parts/regions that make up the facade. The degradation analysis of the facade shows the most common anomalies in each region of the facade and their severity related the areas of occurrence. The degradation mechanism is strongly correlated with the location of the anomalies [25].

This study investigates the most common anomalies in ceramic tiling facades, such as ceramic detachments cracking, grout failure, efflorescence, and infiltration. To this end, the present study focuses on analyzing the intensity and distribution of the different types of degradation in the different facade regions.

\section{Degradation measurement}

The measurement of the degradation is one of the basic steps for evaluating the service life of the building and its elements [11]. For this, the data collected can be associated with long time exposure, especially field exposure, inspection of buildings, exposure of experimental buildings and use exposure. The inspection of buildings allows studying degradation evolution since samples of similar buildings of different ages are examined. When the investigation is designed properly, the result provides a direct correlation of the degradation level of the building, with the exposure conditions (environment), and the use of 
the building [11] The quantification of degradation by inspection identifies the type, extent and location of each anomaly on the facades, and has resulted in a general index degradation. Thus, the degradation can be represented by the degradation index over time, leading to a degradation curve, which allows defining the behaviors regarding service life prediction $[5,11]$.

The measurement of degradation has resulted in a degradation index. Quantification of degradation and the weighed degradation levels are steps of the measurement process. The overall degradation rate is estimated after obtaining the results for these steps.

The Degradation Measurement Method (DMM) was formulated from the study of several cases of degradation of buildings compiled by the Material Testing Laboratory of the University of Brasilia [16]. The DMM consists of three steps: (1) quantification of anomalies, (2) classification and quantification of the level of degradation, and (3) determination of the global degradation index (Degradation General Factor-DGF). This study investigated only the first step.

The degradation is quantified from the data obtained in damage maps. Initially, a $0.50 \times 0.50 \mathrm{~m}\left(0.25 \mathrm{~m}^{2}\right)$ mesh is overlapped on damage mappings, and each mesh is the measurement base unit, shown in Fig. 1 [28]. The degraded area is obtained by simply counting the mesh units, expressed as $\mathrm{m}^{2}$.
The mesh units are counted to determine the total area of the facade, as well as the damaged areas. The degraded areas are counted for each type of anomaly, and any anomalies observed in the mesh unit should be counted, as well.

The DMM may be applied to all facade coating systems, considering the most common anomalies of that system. This method was applied to study ceramic tiling facades [26], considering the following anomalies: ceramic detachment, grouting failure, cracking, efflorescence, and sealing failure. These are the most common anomalies for ceramic tiling facades in Brasília-Brazil [29].

The facades are sampled according to floors and regions as to enable the analysis of degradation along the facade elements and degradation rates among facade regions. Table 1 defines the six facade regions considered in DMM.

The overlapping of the mesh on the anomaly mapping along with the definition of regions (Fig. 1) allows quantifying the distribution of damages as a function of each specific region of the facade [30]. The values obtained represent the percentage of the facade area that degraded, and the sum of these areas is the total area of the facade.

Thus, the aim in this study is to apply the DMM to identify and quantify the anomalies; associate them with the regions where they occur in similar buildings but with different degradation degrees.
Fig. 1 Schematics of damage maps divided into floors and regions

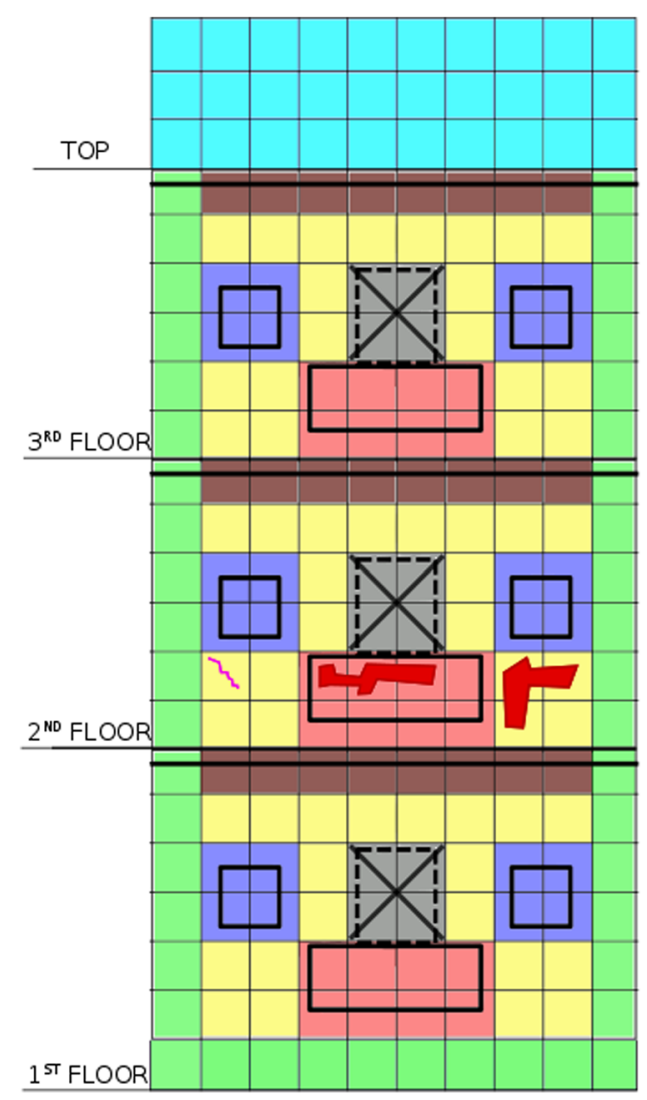

REGIONS

TO - TOP

BA - BALCONIES

FT - TRANSITION BETWEEN FLOORS

OP - OPENINGS

CB - CORNERS AND BORDERS

CW - CONTINUOUS WALLS

HOLOW AREAS

ANOMALIES

CD - CERAMIC DETACHMMENTS

CR - CRAKING 
Table 1 Facade regions considered in DMM

\begin{tabular}{ll}
\hline Region & Description \\
\hline (1) Continuous walls (CW) & Continuous areas (masonry, panels) \\
(2) Openings (OP) & Areas around the openings (windows and hollow elements) \\
(3) Balconies (BA) & Wall areas of the balcony that stand out from the facade plan \\
(4) Corners and borders (CB) & Contour areas of the facade plan \\
(5) Transition between floors (FT) & Facade areas between floors \\
(6) Top (TO) & The upper area of the top of the facade \\
\hline
\end{tabular}

\section{Investigative procedure}

Investigative Procedure consists in study of sample and measurement of degradation. Thus is possible check the regions with higher intensities of damage.

\section{Sample}

From the application of DMM, it was possible to verify the intensity and distribution of anomalies in different regions of the sample buildings. The samples of the facades are from three typical buildings, with construction characteristic of Brasilia. Figure 2 shows the buildings a, b and c; aged 5, 10, and 32 years, respectively. We inspected a total facade area of approximately $9400 \mathrm{~m}^{2}$ covered with ceramic tiles $\left(a-3029 \mathrm{~m}^{2}, \quad b-4055.25 \mathrm{~m}^{2}\right.$ and $\mathrm{c}$ $\left.2312.25 \mathrm{~m}^{2}\right)$.

\section{Degradation measurements-methodology of processing data}

The degradation indexes of the studied facade samples were determined from the quantification of damage obtained by DMM. The indexes were applied after damage was quantified. These indexes are associated with the percentage of the total degraded area and areas that make up the facade. These indices are fundamental to study degradation because they are weighted to allow standardizing the values observed in each region for an adequate comparison between the regions. The division of the facade into regions aims to identify the most critical regions and the most common problems in each region.

Total Degradation Factor $\left(D F_{\text {Total }}\right)$ evaluates the incidence of degraded area over the total area of the facade (sample) (Eq. 1).

$D F_{\text {Total }}=\frac{A_{d}}{A_{t}}$

where $D F_{\text {Total }}$ is the total damage factor, $A_{d}$ is the damaged area, and $A_{t}$ is the facade total area.

Souza [31] and Gaspar [32] reported that different facade regions display different behavior so that there should be a factor damage for individual regions. The damage factor of the regions is calculated similarly to $D F_{\text {Total }}$, but considering the damaged area of the region in relation to the total facade area as shown in Eq. (2).

$D F R=\frac{A_{d r}}{A_{t}}$

where $D F R$ is the damage factor of the regions, $A_{d r}$ is the damaged area of a certain region, and $A_{t}$ is the total sample area. Note that six regions were defined in Table 1.

For the analysis, the facade is divided into its six main regions. Some regions have greater areas, depending on the architectural design of each building. This variation can occur both from building to building and in samples from the same building. Since the degradation factors are measured by the damaged area, it is not possible to compare the degradation
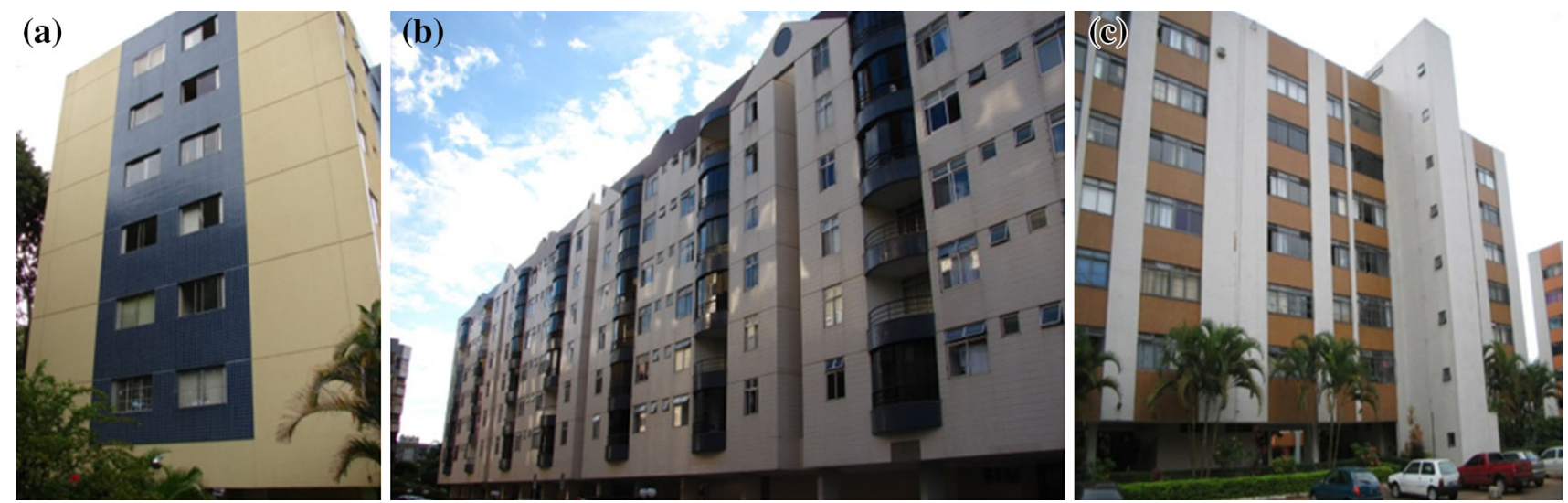

Fig. 2 Studied buildings 
indexes between samples that have regions with different areas. In order to measure and compare the degradation in different regions, in different buildings, it is necessary to establish a factor that standardizes the proportion of regions, thus enabling a coherent analysis in the comparisons.

The correction coefficient of the regions $(\mathrm{CCr})$ is a factor that allows correcting the proportionality of the regions that make up the facade, which is determined for each sample of different building facades. Therefore, the ratio between the smaller area and the area of the studied region (Eq. 3) is used so that higher weights are assigned to smaller areas.

$C C r=\frac{A_{r(m)}}{A_{r(x)}}$

where $C C r$ is the correction coefficient of the regions, $A_{r(m)}$ is the smallest region area, and $A_{r(x)}$ is the area of the studied region.

Table 2 shows the example of a facade sample, $100 \mathrm{~m}^{2}$ (45.6 $\mathrm{m}^{2} \mathrm{CW}, 37.2 \mathrm{~m}^{2} \mathrm{OP}, 2.7,5.8 \mathrm{~m}^{2} \mathrm{FT}$, and $8.7 \mathrm{~m}^{2} \mathrm{TO}$ ) and the smallest area equal to $2.7 \mathrm{~m}^{2}(\mathrm{CB})$ has a $\mathrm{CCr}$ of 0.06 for the $\mathrm{CW}$.

The Degradation Factor of the Standardized Region $\left(D F R_{S T D}\right)$, given by Eq. (4), allows comparing the extent of anomalies in different regions and between different facades (buildings), even if proportions are different between regions. It is important to note that when $D F R$ is corrected, the resulting value is not the degraded area percentage.

$D F R_{S T D}=D F R \times C C r$

where $D F R_{S T D}$ is the degradation factor of the standardized region; $D F R$ is the damage factor of the studied region; and $\mathrm{CCr}$ is the correction coefficient of the studied region.

\section{Results and discussion}

Table 3 shows the $D F_{\text {Total }}$ and $D F R$ indices that resulted from the mapping and analysis of the extent of the area of anomalies in the buildings, considering total area as well as of individual buildings area.
For all three buildings, the highest percentage of degraded area is observed in the $\mathrm{CW}$ region, followed by FT, TO, CB, OP, and BA. The $\mathrm{CW}$ region has more than $65 \%(11.41 / 17.42)$ of degraded area (mainly by building $\mathrm{C}$ contribution). The sum of the percentage of degraded areas (DFR) is equivalent to the percentage of the total degraded area $\left(D F_{\text {Total }}\right)$ because $D F_{\text {Total }}$ and $D F R$ are calculated on the total area of the building facade.

The $\mathrm{CB}, \mathrm{CW}$, and $\mathrm{TO}$ regions had the largest degraded areas in building a, representing approximately $86 \%$ of the degradation in this new building. In building a, the OP and FT regions had low values of degraded areas, indicating that newer buildings may have lower incidence of damage in these regions. The largest damaged areas in building $b$ were observed in CW and FT, representing almost $63 \%$ of the damaged area. On the other hand, the TO and BA regions had the smallest damaged area. Also, the $\mathrm{CW}$ area of building c represented almost $70 \%$ of the damaged area. The FT and TO regions of building c facade are regions with significant levels of degradation as well.

Figure 3 shows the percentage values of the damaged areas of the studied buildings' regions, allowing to visualize the percentage area with and without damage, in addition to the degradation percentage of each region.

Figure 4 shows that the $D F R$ and $D F_{\text {Total }}$ values increased from newer to older buildings, resulting from the fact that degradation increases over time. Moreover, the PC region is always among the regions with the largest degraded areas, corroborating the results of Silva [29] and Silva [30].

The regions with largest damage areas are the continuous walls $(\mathrm{CW})$, which are extensive ceramic coating plans. The absence or faulty horizontal and vertical movement joints hinder the performance of this region due to its own tensions. Stress arising from the different behaviors of the layers that make up the coating system, added to the stress transferred by the deformations of the reinforced concrete structure, the masonry, and hygrothermal variations that act on different elements and components of this system, result in system failure

Table $2 \mathrm{CCr}$ calculated for continuous walls $(\mathrm{CW})$ for the above example

\begin{tabular}{|c|c|c|c|c|c|}
\hline \multirow{2}{*}{$\begin{array}{l}\text { Total area of } \\
\text { the facade sample }\left(\mathrm{m}^{2}\right) \\
100.0\end{array}$} & \multicolumn{2}{|c|}{$\begin{array}{l}\text { Areas of } \\
\text { the different regions }\left(\mathrm{m}^{2}\right)\end{array}$} & \multirow{2}{*}{$\begin{array}{l}\text { Area of the smallest } \\
\text { region }\left(\mathrm{m}^{2}\right)\end{array}$} & \multirow{2}{*}{$\begin{array}{l}\text { Area of the analyzed } \\
\text { region }\left(\mathrm{m}^{2}\right)\end{array}$} & \multirow{2}{*}{$\begin{array}{l}C C r_{(\mathrm{CW})} \\
C C r_{(\mathrm{CW})}=\frac{2.7}{45.6}\end{array}$} \\
\hline & $\mathrm{CW}$ & 45.6 & & & \\
\hline & OP & 37.2 & & & \\
\hline & BA & 0.0 & & & \\
\hline & $\mathrm{CB}$ & 2.7 & & & $C C r_{(C W)} \cong 0.06$ \\
\hline & FT & 5.8 & & & \\
\hline & TO & 8.7 & & & \\
\hline
\end{tabular}


Table 3 The $D F_{\text {Total }}$ and $D F R$ indices for the regions of the studied buildings

\begin{tabular}{lllll}
\hline Region & \multicolumn{4}{l}{ DFR } \\
\cline { 2 - 5 } & All buildings (\%) & Building A (\%) & Building B (\%) & Building C (\%) \\
\hline Continuous walls (CW) & 11.41 & 0.27 & 3.68 & 39.56 \\
Openings (OP) & 0.90 & 0.11 & 1.49 & 0.90 \\
Balconies (BA) & 0.19 & 0.00 & 0.44 & 0.00 \\
Corners and borders (CB) & 1.38 & 0.26 & 1.48 & 2.69 \\
Transition between floors (FT) & 2.06 & 0.02 & 2.31 & 4.31 \\
Top (TO) & 1.48 & 0.30 & 0.18 & 5.29 \\
DF $_{\text {Total }}$ & 17.42 & 0.96 & 9.58 & 52.75 \\
\hline
\end{tabular}

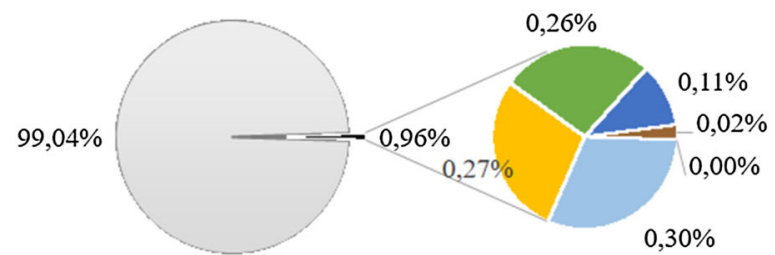

$\square$ Good condition $₫ \mathrm{TO}$ (damaged) $\| \mathrm{CW}$ (damaged) $\| \mathrm{CB}$ (damaged) $\because \mathrm{OP}$ (damaged) $\quad$ FT (damaged) $\quad$ BA (damaged)

(a)

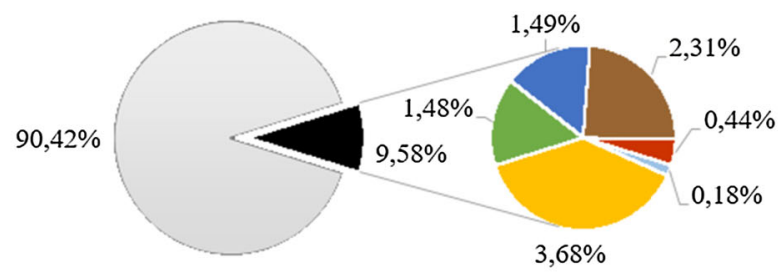

$\square$ Good condition $\| \mathrm{TO}$ (damaged) $\| \mathrm{CW}$ (damaged) $\| \mathrm{CB}$ (damaged) $\| \mathrm{OP}$ (damaged) $\quad$ FT (damaged) $\quad \mathrm{BA}$ (damaged)

(b)

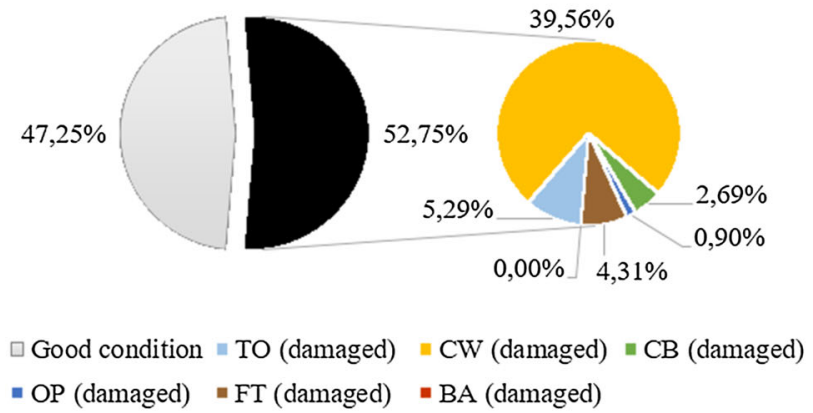

(c)

Fig. 3 Percentages of the damaged areas in the regions of buildings

$[6,13,23]$. The design process (specification of components, cover layers, and determination of settlement and movement joints) and implementation should be carefully planned to ensure the best performance of the coating system $[9,18,20]$.

Except for $\mathrm{CW}$, the regions that stand out with evident damage are TO and CB in building a; FT, $\mathrm{CB}$ and $\mathrm{OP}$, in building $\mathrm{b}$; and $\mathrm{TO}$ and FT, in building $\mathrm{c}$. The high percentage of anomalies in CW, TO, FT and CB demonstrated the vulnerability of these regions to the occurrence of anomalies, so it is assumed that the concentration of mechanical and thermal stresses is a factor in these regions [16].

The CB regions had large degraded areas, which may result from the expansion or contraction movements due to heat and/or humidity. In the FT regions, masonry and structure are in direct contact, and the different materials respond differently to the imposed demands, causing damage to the interfaces. Therefore, in the FT region, the localized damage results from absent or faulty movement joints. These anomalies are common in TO regions since these areas are the most exposed to sunlight and rain.

Table 4 shows the $\mathrm{CCr}$ of the three buildings analyzed in this study.

Because the regions of the facades have different areas and degradation is measured in units of area, the $D F R$ index needs to be weighted so it can be used to compare the degradation of the various regions consistently.

The comparison of the extent of the anomalies in different regions may be influenced by regions with larger 
Fig. 4 DFR and $D F R_{S T D}$ for the regions of buildings $\mathbf{a}, \mathbf{b}$, and $\mathbf{c}$

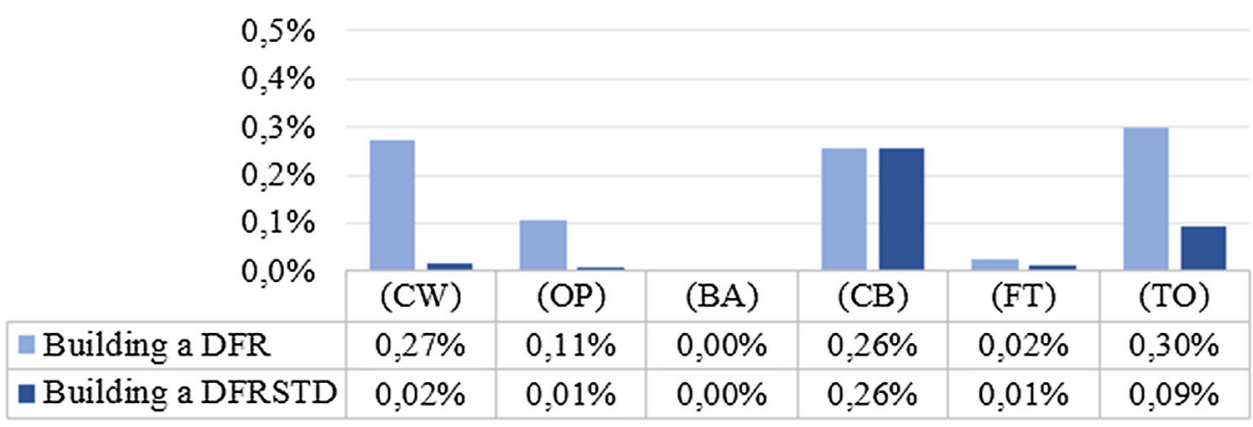

(a)

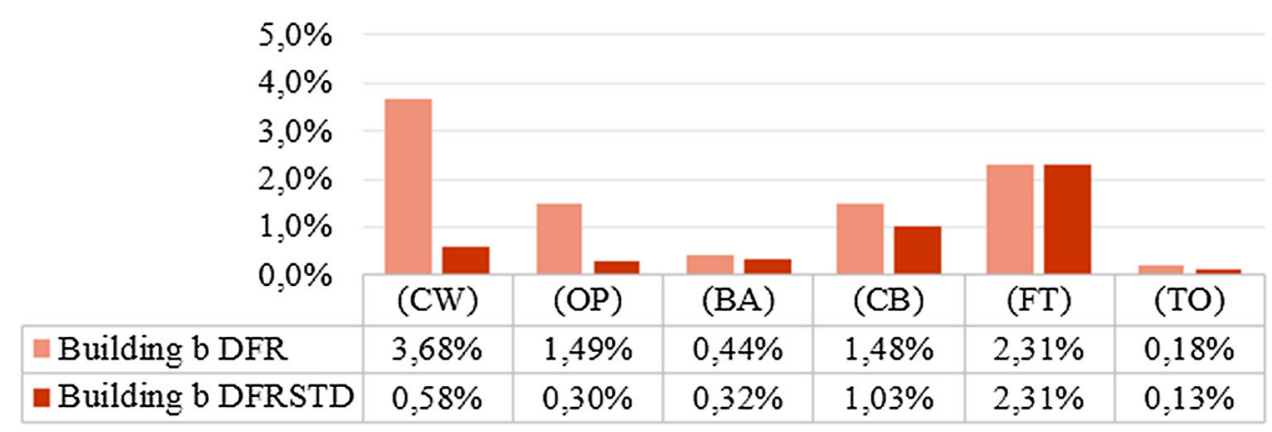

(b)

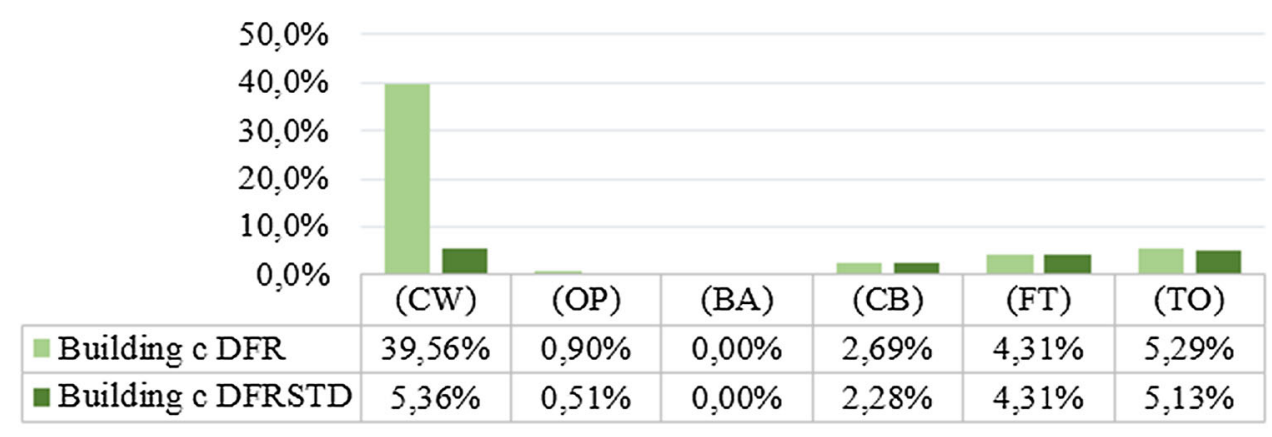

(c)

Table 4 Correction coefficient of the regions $(\mathrm{CCr})$

\begin{tabular}{llll}
\hline CCr & Building A & Building B & Building C \\
\hline CW & 0.06 & 0.16 & 0.14 \\
OP & 0.07 & 0.20 & 0.56 \\
BA & 0.00 & 0.74 & 0.00 \\
CB & 1.00 & 0.69 & 0.85 \\
FT & 0.48 & 1.00 & 1.00 \\
TO & 0.31 & 0.73 & 0.97 \\
\hline
\end{tabular}

areas, as they may present a degradation percentage higher than other regions. The use of $\mathrm{CCr}$ corrects the values according to the proportionality of the regions that make up the facade. Figure 4 shows DFR and $D F R_{S T D} .0$ for the building $\mathrm{a}, \mathrm{b}$ and $\mathrm{c}$ regions.
The figure shows that the TO area of building a has the highest DFR $(0.30 \%)$, which after corrected, shows that the highest $D F R_{S T D}(0.26 \%)$ occurs in the $\mathrm{CB}$ region. This fact demonstrates that larger areas may have smaller degradation intensities, compared with less representative areas. It can be seen in Fig. 4a that the most damaged regions are $\mathrm{CB}$ followed by the $\mathrm{TO}$ region while all other regions had almost no damage.

Building b presents the highest $D F R$ values for the $\mathrm{CW}$ (3.68\%) followed by the TP (2.31\%), OP (1.49\%), CB $(1.48 \%)$, BA $(0.44 \%)$, and TO $(0.18 \%)$ regions. But, when the DFR values are corrected, Fig. $4 \mathrm{~b}$ shows that the intensity of damage is greater in the TP $(2.31 \%)$ and $\mathrm{CB}$ $(1.03 \%)$ regions, followed by $\mathrm{CW}(0.58 \%)$, BA $(0.32 \%)$, OP $(0.30 \%)$ and TO $(0.13 \%)$. Therefore, after correcting the $D F R$, the intensity of damage is greater in the TP than in the $\mathrm{CW}$ region in building $\mathrm{b}$. 
Figure 4c shows that DFR is significantly higher for $\mathrm{CW}$ than other regions, and even after correction, the highest $D F R_{S T D}$ is observed in the CW area. However, after correction, the $D F R_{S T D}$ values are no longer discrepant among the studied regions. The major degradation values represented by $D F R_{S T D}$ occur in the regions of $\mathrm{CW}(5.36 \%)$, TO $(5.13 \%)$, FT $(4.31 \%)$, followed by CB $(2.28 \%)$ and OP $(0.51 \%)$ regions.

It is noteworthy the different order of magnitude of the degradation indexes ( $D F R$ and $D F R_{S T D}$ ) for the three buildings in Fig. 4, the highest values occurred for older buildings. The newest building is an order of magnitude above the average age of the building, and the oldest building is an order of magnitude below the average age of the building.

The regions with the greatest degradation intensity varied among the three buildings. The region with the highest degradation intensity is the corners and edges $(0.26 \%)$ region in building a. On the other hand, in building $\mathrm{b}$ is the FT $(2.31 \%)$ region, followed by $\mathrm{CB}$ $(1.03 \%)$ while in building $\mathrm{c}$, is the $\mathrm{CW}(5.36 \%)$ region, followed by TO $(5.13 \%)$ and FT $(4.31 \%)$. The older buildings showed higher degradation intensity.

\section{Conclusions}

This study proposes to apply a damage factor to building regions, based on data from three buildings whose characteristics are typical of the construction systems of residential buildings in Brasilia, DF. The data obtained from the mapping of the three buildings allow concluding that:

(a) The methodology analyzed was efficient in evaluating the degradation due to age. It is possible to quantitatively observe the degradation behavior difference in the various regions, which make up the facade, which allows more specific analysis such as the study of weather degradation on buildings.

(b) The most degraded regions are essentially $\mathrm{CW}$, TO and FT. This result converge with field observations and represent elements notoriously subject to higher requests.

(c) Although the $D F R_{S T D}$ is not a physical parameter to measure degradation, it is important to allow the comparison of different regions of the facades. The most affected regions are the $\mathrm{CW}$ but not always with the greatest damage intensity. The different construction process, design, exposure to degradation agents and even maintenance actions can explain the variation of degradation intensities of different regions $\left(D F R_{S T D}\right)$ at different ages.
Acknowledgments Thanks are due to the Universidade de Brasília, the graduate program in Estruturas e Construção Civil (PECC), Conselho Nacional de Desenvolvimento Científico e Tecnológico $(\mathrm{CNPq})$ for the financial support and to the LEM/UnB for providing the inspection files.

\section{References}

1. Silva AFF, Viera SM, Brito J, Gaspar PL (2016) Fuzzy systems in the service-life prediction of exterior natural stone claddings. J Perform Constr Facil. doi:10.1061/(ASCE)CF.1943-5509.0000860

2. Gonçalves A, Brito J, Amaro B (2014) Systematic approach to inspect, diagnose, and repair masonry walls. J Perform Constr Facil. doi:10.1061/(ASCE)CF.1943-5509.0000650 (in Portuguese)

3. Flores I (2002) Maintenance strategies: current building's envelope. Master Thesis, Instituto Superior Técnico (IST), Lisboa. (in Portuguese)

4. Silva AFF (2009) Methodology for service life prediction of external walls natural stone cladding. Master Thesis, Instituto Superior Técnico (IST), Lisboa. (in Portuguese)

5. Jernberg P, Sjostrom C, Lacasse MA, Brandt E, Siemes T (2004) Service life and durabilityresearch. In: Guide and Bibliography to Service Life and Durability Research for Buildings and Components. CIB Publication 295, pp 11-59

6. Silvestre JD, Flores-Colen IS, Brito J (2005) Strategy proactive maintenance for joints in adhesive ceramic tiling (ACT). In: 1 Congresso Nacional de Argamassas de Construção, Lisboa, pp 1-12. (in Portuguese)

7. Bordalo R, Brito J, Gaspar PL, Silva A (2010) Service life prediction modelling of adhesive ceramic tiling systems. Teoria e Prática da Engenharia Civil 16:55-69 (in Portuguese)

8. Flores-Colen IS, Brito J (2010) A systematic approach for maintenance budgeting of buildings facades based on predictive and preventive strategies. Constr Build Mater 24:1718-1729

9. Gaspar P (2009) Service life of buildings: methodology for service life prediction of building components. Application to external cement-renders. PhD Thesis, Instituto Superior Técnico (IST), Lisboa (in Portuguese)

10. Santos MRP (2010) Methodologies of life prediction of materials, systems and building components. Master Thesis, Faculdade de Engenharia da Universidade do Porto (FEUP), Porto (in Portuguese)

11. ISO/DIS 15686-2 (2012) Buildings—-service life planning. Part 2: Service life prediction procedures, International Organization for Standardization, London

12. Associação Brasileira de Normas Técnicas (2013) ABNT NBR 15575-1 Edificações habitacionais-Desempenho-Parte 1: Requisitos gerais. Rio de Janeiro

13. Bauer E, Castro EK, Silva MNB (2012) Quantitative analysis of damage in facade coating systems in Brasília. In: XIV Encontro Nacional de Tecnologia do Ambiente Construído-XIV ENTAC, vol 1, Juiz de Fora, pp 2015-2020 (in Portuguese)

14. Gaspar PL, Brito J (2008) Quantifying environmental effects on cement-rendered facades: a comparison between different degradation indicators. Build Environ 43:1818-1828

15. Shohet IM, Rosenfeld Y, Puterman M, Gilboa E (1999) Deterioration patterns formaintenance management-a methodological approach. In: VIII DBMC - Durability of BuildingMaterials and Components, 2, Ottawa, pp 1666-1678

16. Silva MNB (2014) Quantitative evaluation of degradation and service life of facadés coatings - application to Case of Brasilia/ Brazil, PhD Thesis, University of Brasília, Brazil (in Portuguese) 
17. Sousa RD (2008) Prediction of the service life of external ceramic wall tiling laid on mortar or adhesive. Master Thesis, Instituto Superior Técnico (IST), Lisboa (in Portuguese)

18. Bauer E, Silva MNB, Zanoni VAG (2015) Measurement of degradation and service life in facades. In: XI Simpósio Brasileiro de Tecnologia das Argamassas XI SBTA. Porto Alegre. (in Portuguese)

19. Flores-Colen IS (2009) Methodology for in-service performance assessment of rendering facades for predictive maintenance. $\mathrm{PhD}$ Thesis, Instituto Superior Técnico (IST), Lisboa (in Portuguese)

20. Bauer E, Castro EK, Silva MNB, Zanoni VAG (2014) Evaluation of damage of building facades in Brasília. DBMC Durab Build Mater Compon 1:535-542

21. Zanoni VAG, Sánchez JMM, Bauer E, Amorim CND (2014) Driving rain index (DRI) analysis matrix to the city of BrasiliaDF. PARANOÁ (cadernos de arquitetura e urbanismo)-Conforto e Projeto: Cidades. No 11, Brasília, pp 67-76 (in Portuguese)

22. Nascimento MLM, Souza JS, Zanoni VAG, Bauer E (2016) Wind-driven rain incidence parameters obtained by hygrothermal simulation. In: CBPAT—Congresso Brasileiro de Patologia das Construções (in Portuguese)

23. Bauer E, Castro EK, Silva MNB (2015) Estimate of the facades degradation with ceramic cladding: study of Brasilia buildings. Cerâmica 61:151-159

24. Galbusera MM (2013) Application of the factor method to the prediction of the service life of ceramic external wall claddings. $\mathrm{PhD}$ Thesis, Instituto Superior Técnico (IST), Lisboa
25. Antunes GR (2010) Study of pathological manifestations in facade coating in Brasília-systematization of cases' occurrences. Master Thesis, University of Brasília, Brazil (in Portuguese)

26. Souza JS (2016) Evolution of facades degradation-effect of degradation agents and constituent elements. Master Thesis, University of Brasília, Brazil (in Portuguese)

27. Hovde PJ (2004) Factor methods for service life prediction. In: Performance based methods for service life prediction. CIB Publication 294, pp 1-51

28. Bauer E, Silva MNB, Zanoni VAG, Castro EK (2015) Degradations curves of building facade in Brasilia, Brazil. In: CONPAT-XIII Congr Latino-Americano Patol da Construção, pp 0-7 (in Portuguese)

29. Silva MNB, Bauer E, Castro EK, Zanoni VAG (2014) Damages and pathology distribution in facades Brasilia-case study. In: Simpósio Argamassa e soluções térmicas em Revestimentos. APFAC, Coimbra (in Portuguese)

30. Silva MNB, Bauer E, Castro EK (2014) Assessment of degradation in coating ceramic systems facade in Brasilia. In: Simpósio Argamassa e soluções térmicas Revest (in Portuguese)

31. Souza JS, Nascimento MLM, Bauer E (2015) Study of quantification of degradation building facades by damage maps. In: IV Congresso Internacional na Recuperação, Manutenção e Restauração de Edifícios - IV CIRMARE. UFRJ, Rio de Janeiro. (in Portuguese)

32. Gaspar P, Brito J (2005) Mapping defect sensitivity in external mortar renders. Constr Build Mater 19:571-578 